\title{
TÓPICO DISCURSIVO E TABU COMUNICATIVO EM UM RELATO SHIPIBO-KONIBO
}

\author{
DISCURSIVE TOPIC AND COMMUNICATIVE TABOO IN \\ SHIPIBO-KONIBO ACCOUNT
}

\author{
Raphael Augusto Oliveira BARBOSA ${ }^{1}$ \\ Renato Cabral REZENDE²
}

\begin{abstract}
Resumo: A comunicação verbal que, tradicionalmente, envolve a relação de parentesco entre sogro(a) e genro (denominados rayos na língua Shipibo-Konibo) não se realiza diretamente entre eles, mas somente por intermédio da filha/ esposa correspondente. No presente trabalho, com foco na perspectiva textual e sociocognitiva interacional, analisamos esse aspecto comunicativo em um relato oral transcrito na gramática da língua, intitulada "Transitividade na Gramática ShipiboKonibo" (VALENZUELA, 2003). Nos contextos de interação identificados no relato, examinamos se, e de que maneira, as estratégias de organização do tópico discursivo indicam a dinâmica deste aspecto interacional de distância/proximidade entre rayos. Para isso, descrevemos o quadro tópico, que consiste em representação de uma interação, e analisamos os processos de gestão tópica e referenciação, realizados pelos participantes do relato. Conforme os resultados, argumentamos que os processos de gestão tópica revelam a proximidade interacional dos sujeitos presentes nos contextos de interação. Assim, as representações das situações socioculturais no relato refletem contrastes dos contextos de interação do passado e do presente, o que indica prováveis mudanças nas relações sociointeracionais entre rayos.
\end{abstract}

Palavras-chave: Linguística Textual. Sociolinguística Interacional. Tabu Comunicativo. Shipibo-Konibo. Família Pano.

\begin{abstract}
Verbal communication involving the kinship relationship between mother-in-law orfatherin-law and son-in-law (called rayos in the ShipiboKonibo language) does not take place directly between them, but only through the corresponding daughter/wife. In this paper, focusing on the textual and sociocognitive interactional perspective, we analyze this communicative aspect in an oral account transcribed in the grammar of the language, entitled "Transitivity in Shipibo-Konibo Grammar" (VALENZUELA, 2003). In the contexts of interaction identified in the account, we examined whether and how the organizing strategies of the discursive topic indicate the variability of this interactional aspect. First, we describe the topical framework and then analyze the topical management and referential processes of its participants. According to the results, we argue that the topical management processes reveal the interactional proximity of the subjects in the contexts of interaction. Thus, the representations of socio-cultural situations in the account reflect past-present contrast of interactional contexts, which indicates probable changes in socio-interactional relations between rayos.
\end{abstract}

Keywords: Text Linguistics. Interactional Sociolinguistics. Taboo of Communication. ShipiboKonibo. Panoan Family.

\footnotetext{
1 Barbosa. USP. E-mail: raphael.aob@gmail.com._ORCID: https://orcid.org/0000-0001-7719-6169 
- | Tópico discursivo e tabu comunicativo em um relato Shipibo-Konibo

\section{Introdução}

No presente trabalho apresentamos os resultados da análise textual, de base sociointeracional, a respeito da organização do tópico discursivo em um relato oral na língua Shipibo-Konibo, sobre a relação entre rayos 'sogros(as)' e 'genros'. Os ShipiboKonibo são um povo indígena da Amazônia peruana, cuja língua de mesmo nome pertence à família Pano. A língua Shipibo-Konibo é caracterizada como aglutinante, sintética e sufixal. O alinhamento morfossintático é do tipo ergativo-absolutivo, com os casos ergativo, genitivo, instrumental e locativo marcados com o morfema $\{-n\}$. Os pronomes pessoais e possessivos fazem referência à primeira, segunda e terceira pessoa, com distinção de número (singular e plural). A língua possui sistema de concordância de participante, referência-alternada, e de evidencialidade que distingue fontes de informação primária e secundária, e, ainda que a ordem dos constituintes seja flexível, verbos de orações subordinadas ocorrem na posição final (VALENZUELA, 2003).

O texto na língua Shipibo-Konibo que analisamos foi publicado por Valenzuela (2003), disponível na seção de anexos da descrição gramatical da língua, e contém a tradução para o Inglês e o Espanhol. A tradução que realizamos para o Português, utilizada neste trabalho, tem como base tanto as versões Inglês e Espanhol quanto, em especial, o texto fonte na língua Shipibo-Konibo. O trabalho intitulado "Transitividade na Gramática Shipibo-Konibo" (Transitivity in Shipibo-Konibo Grammar), que tem como objetivo descrever e documentar a língua, é estruturado em duas partes básicas, em que a autora apresenta, inicialmente, os aspectos fonológicos, morfológicos, sintáticos e pragmáticos, e, na segunda parte, a análise morfossintática da categoria funcional de transitividade.

A língua Shipibo-Konibo é falada por uma população de aproximadamente 30.000 indivíduos. Seus falantes se identificam como shipibo ou jonikon ${ }^{3}$ e, com uma média de 130 aldeias, estão localizados nos Departamentos de Ucayali, Loreto, Huánuco e Madre de Dios - Peru (VALENZUELA, 2003). Esse idioma pertence à família linguística Pano que se constitui de cerca de 30 línguas, das quais aproximadamente 20 são faladas atualmente nos territórios do Brasil, Peru e Bolívia (FLECK, 2013). Assim como as línguas KashiboKakataibo (ZARIQUIEY, 2011) e Matsés (FLECK, 2013), o Shipibo-Konibo é atualmente uma das línguas mais estudadas da família Pano.

\footnotetext{
$3 \mathrm{Em}$ termos gerais, o nome jonikon 'pessoas verdadeiras' (também usado por outros povos pano como os Kashinawa e alguns Yaminawa e Amawaka) corresponde à autodenominação de três antigas unidades étnicas diferentes que habitavam partes distintas do rio Ucayali. Estes três povos que se uniram no século $X X$, constituindo uma só unidade atualmente, foram chamados de Shipibo, Konibo (grupos maiores e mais dominantes) e Xetebo. A palavra 'shipibo' corresponde à raiz morfológica shipi - 'sagui' e \{-bo\} - sufixo marcador de pluralidade (cf. VALENZUELA, 2003).
} 
O relato textual em análise trata de um aspecto tradicional do povo ShipiboKonibo, que restringe a interação entre parentes por afinidade denominados pela palavra rayos, traduzida aqui basicamente como 'sogros(as)' e 'genros'. Devido a esse aspecto sociolinguístico, indivíduos com essa relação de parentesco por afinidade não se falam diretamente, mas se comunicam por meio da filha/esposa correspondente. Conforme Valenzuela (2003), esse aspecto também se estende aos avós paternos e à tia materna da filha/esposa ${ }^{4}$.

Com a análise textual desse relato, nosso objetivo é verificar se e como as estratégias de gestão do tópico discursivo revelam a variabilidade das condições atuais desse aspecto interacional dos Shipibo-Konibo, a saber, de que a relação de parentesco entre sogro(a) e genro não se realiza diretamente entre eles, mas somente por intermédio da filha/esposa correspondente. Nesse sentido, o presente estudo é motivado pela ausência de análises sociolinguísticas e etnointeracionais em sociedades indígenas e pela sua relevância para o entendimento da relação dos aspectos linguístico-textuais, culturais e sociais dessas comunidades. A seção seguinte apresenta os materiais utilizados e os princípios teóricos e metodológicos considerados no desenvolvimento deste trabalho.

\section{Material e método}

O relato textual em análise no presente estudo é extraído da seção de anexos do trabalho de descrição linguística do idioma Shipibo-Konibo (VALENZUELA, 2003). De acordo com a autora supracitada, esse relato, proferido por uma falante dessa língua chamada Ranin Ama (ca. 40 anos) e registrado no Departamento de Ucayali - Peru, no ano de 1998, diz respeito a aspectos comunicativos desse povo. Com base nesse material, aplicamos princípios metodológicos de análise textual em relato de interação da referida sociedade indígena com vistas a compreender aspectos sociolinguísticos e antropológicos dessa comunidade.

Com base em princípios que compõem noções fundamentais no que diz respeito às concepções de língua, sujeito, texto e sentido, a perspectiva teórico-metodológica que preside à discussão do relato em análise corresponde à abordagem sociocognitivo-

\footnotetext{
4 Conforme Valenzuela (2003, p. 17, tradução nossa): “Mesmo em um situação na qual um sogro e um genro viajam para longe e permanecem sem contato com outras pessoas por algum tempo, não devem falar um com o outro diretamente e podem se comportar como se a filha ou esposa estivessem presentes, fingindo que se comunicam por meio delas.". No original: "Even in a situation when a father-in-law and his son-in-law travel far away and remain without contact with any other person for some time, they are not supposed to talk to each other directly and may behave as if the daughter or wife were present pretending they communicate through her.".
} 
- | Tópico discursivo e tabu comunicativo em um relato Shipibo-Konibo

interacional (BENTES, 2007; JUBRAN, 2006; KOCH, 1992; MONDADA; DUBOIS, 2003; REZENDE, 2006). A análise baseada na categoria de tópico discursivo apresenta um enfoque pragmático-interacional da linguagem e por isso não se limita à descrição tradicional com o recorte estrito da frase como unidade isolada de análise. Nesse sentido, com a descrição do tópico discursivo, buscamos analisar suas unidades no nível linear e hierárquico.

Os princípios de construção textual do sentido do tópico discursivo referem-se aos seguintes critérios de textualização: coesão, coerência, situacionalidade, informatividade, intertextualidade, intencionalidade, aceitabilidade, contextualização, consistência e relevância, focalização, conhecimento pressuposto e compartilhado (BEAUGRANDE; DRESSLER, 1981). Os princípios e critérios de textualização no relato selecionado foram analisados com base nas propriedades que apresentam maior relevância para o objetivo do trabalho e com isso não pretendemos realizar um exame exaustivo de todos os aspectos dessas propriedades.

Tendo em vista que o processo de alternância dos tópicos discursivos representa um aspecto constitutivo do texto, essa categoria também permite maior abrangência analítica de gêneros textuais orais e escritos, pois ela não se restringe ao turno conversacional, específico de textos dialogais (JUBRAN, 2006). Em princípio, a análise do presente estudo baseia-se nos conceitos de centração e de organicidade como propriedades definidoras da categoria analítica de tópico, em termos de funções interacionais e de interdependência sequencial e hierárquica de suas unidades. Sobre os aspectos da centração, Jubran (2006, p. 35) os define nos seguintes termos:

Concernência: relação de interdependência entre elementos textuais, firmada por mecanismos coesivos de sequenciação e referenciação, que promovem a integração desses elementos em um conjunto referencial, instaurado no texto como alvo da interação verbal; Relevância: proeminência de elementos textuais na constituição desse conjunto referencial, que são projetados como focais, tendo em vista o processo interativo; Pontualização: localização desse conjunto em determinado ponto do texto, fundamentada na integração (concernência) e na proeminência (relevância) de seus elementos, instituídas com finalidades interacionais.

A organicidade tópica se caracteriza pela interdependência hierárquica e sequencial das unidades discursivas, cujo estabelecimento constitui-se respectivamente no plano vertical pelo grau de abrangência do tópico, e no linear pelas articulações inter e intratópicas na linha do discurso. Em geral, no plano linear, essas relações 
se estabelecem pela adjacência e interposição tópica em termos de continuidade sequencial e descontinuidade por inserção e/ou alternância. No plano vertical, as relações de interdependência entre as camadas hierárquicas constituem o Quadro Tópico representado por dimensões escalares (JUBRAN, 2006).

De acordo com as palavras de Jubran (2006, p. 40): "Na construção tópica, a função interacional conjuga-se com a referencial de forma que as propriedades de concernência, relevância e pontualização da centração são sempre instituídas com finalidades interativas.". Nesse sentido, analisamos a organização tópica com base em suas propriedades interativas e suas relações de referências léxico-nominais e contextuais, as quais marcam as relações discursivas e temporais presentes no relato. A apresentação e representação dos referentes por meio de rótulos que demonstram o grau de subjetividade da fonte enunciativa baseia-se no conceito de referenciação definido por Mondada e Dubois (2003).

A noção de referenciação adotada no presente estudo corresponde a uma "visão dinâmica que leva em conta não somente o sujeito 'encarnado', mas ainda um sujeito sociocognitivo mediante uma relação indireta entre os discursos e o mundo" (MONDADA; DUBOIS, 2003, p. 20). Nesse sentido, essa definição do termo referenciação, que vai além da noção básica de referência língua-mundo, apresenta-se fundamentalmente como um processo linguístico sociocognitivo-interacional que organiza o direcionamento da categoria de tópico no discurso por meio das relações socioculturais dos participantes do evento.

A definição de Quadro Tópico adotada neste trabalho é basicamente apresentada como um conceito relacional constituído por um tópico mais abrangente (supertópico) composto internamente por tópicos co-constituintes em uma mesma camada (subtópicos), e suas possíveis divisões sucessivas no interior de cada subtópico coconstituinte (JUBRAN et al., 2002; JUBRAN, 2006). Em suma, o Quadro Tópico representa a relação de interdependência entre os níveis tópicos discursivos, com cada nível tópico superior compondo os níveis inferiores.

\section{Discussão e resultados}

Apresentamos a seguir o Quadro Tópico (doravante QT) e a configuração da gestão do tópico discursivo (supertópico, subtópicos e segmentos tópicos) identificado no relato analisado: 
- | Tópico discursivo e tabu comunicativo em um relato Shipibo-Konibo

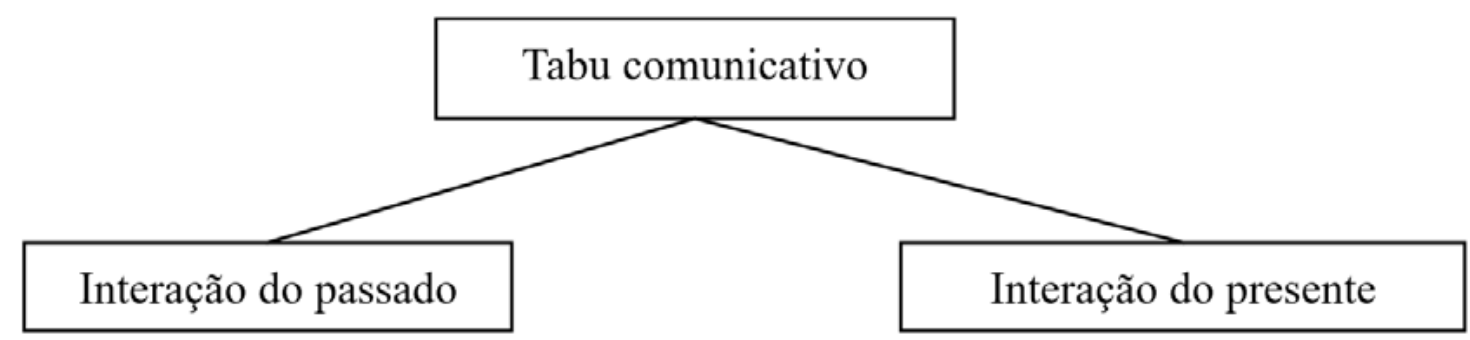

Os referentes presentes no relato correspondem aos participantes 'filha/esposa', 'sogra' e 'genro', que compõem os tópicos discursivos nas descrições de interação entre rayos 'sogros(as)' e 'genros'. Os segmentos tópicos (unidades que atualizam o aspecto organizacional do tópico discursivo) e suas correspondências com os subtópicos do QT são apresentados a seguir:

Quadro 1. Relação hierárquica do Quadro Tópico 'tabu comunicativo'

\begin{tabular}{|c|c|c|c|}
\hline Supertópico & Subtópicos & Segmentos tópic & \\
\hline \multirow{10}{*}{$\begin{array}{c}\text { Tabu } \\
\text { comunicativo }\end{array}$} & \multirow{7}{*}{ Interação do passado } & 1. caracterização & [a] \\
\hline & & 2. interação mediada & [b] \\
\hline & & 3. justificativa & [c] \\
\hline & & 4. distanciamento & [e] \\
\hline & & 5. contato visual & {$[\mathrm{g}]$} \\
\hline & & 6. pedido ao genro & [h] \\
\hline & & 7. cumprimento impessoal & [i] \\
\hline & \multirow{3}{*}{ Interação do presente } & 8. interação não mediada & [d] \\
\hline & & 9. aproximação espacial & {$[\mathrm{f}]$} \\
\hline & & 10. mudança na interação & [j] \\
\hline
\end{tabular}

Fonte: Elaboração própria

Nesse quadro, a dimensão linear é representada com base na dimensão da organização hierárquica (1 a 10), baseada na relação de subordinação dessas unidades com cada camada tópica correspondente, e no sequenciamento dos segmentos tópicos no nível textual ([a] a [j]). De acordo com essa estrutura de apresentação, as relações de organização do tópico discursivo com os processos de referenciação na construção dos objetos de discurso serão analisadas e discutidas na próxima seção. 
Nesse sentido, analisaremos a construção referencial dos objetos de discurso e os segmentos tópicos que constituem o QT. Os objetos de referenciação analisados correspondem aos participantes 'sogra', 'filha/esposa' e 'genro'. Sendo assim, a análise será focada na referência ao 'genro', tendo em vista a maior variação deste objeto referencial em situações e eventos comunicativos representados com o verbo yoyo, traduzido por 'falar, dizer, contar, conversar, pedir, perguntar'.

\section{Interação do passado}

A relação dos subtópicos 'interação do passado' e 'interação do presente' compõem o supertópico 'tabu comunicativo', conforme o QT e seus segmentos. Na introdução do relato, o subtópico 'interação do passado' é aberto com a 'caracterização' geral dos participantes e suas relações na comunidade. Assim, essa descrição é desenvolvida conforme os subtópicos apresentados a seguir:

(1) Jawetianbira, non rayos yoyo ayosma iki, 'Tradicionalmente, nós nunca somos de conversar com os genros,' non beneitsa jisama iki. '(eles) não são vistos como nossos cunhados. ${ }^{5}$

(2) Jawetianbi, non "jowe ranon!" ayosma iki, 'Sendo assim, nós nunca somos de dizer (a eles): "venha aqui jovem!", “xonta, jonon min bene!", akin akai, '(ao contrário), (nós) dizemos (a elas): "garota, seu esposo pode vir!",' jatian, jawen rayos "jee, jee" ikai. 'então, os genros respondem: "sim, sim" (com todo o respeito). Jatian bakeranonanbiribi "tita jonon, Biri", akin akai, 'Por sua parte o jovenzinho diz (a ela): "Biri, (su)a mãe pode vir!",' jatian "joo" ikai. 'então (nós) respondemos: "sim".'

(3) Ramakamanbinoa non rayos betan yoyo iamaai, noajaskara iki. 'Até hoje nós não falamos diretamente com nossos genros, nós somos assim.' Wetsankobo kaaibi non oinoinresai non rayos. 'Mesmo que (eles) fossem a outros lugares, nós somente olhamos para nossos genros.' Non jawe ikemein, non bene ikemein, rayos non yokati iki. '(eles) seriam talvez nossos 'alguma coisa', ou (eles) seriam talvez nossos esposos para, aos genros, nós fazermos perguntas?' Jakonshoko akinres non rayos atijake. '(nós) devemos respeitar nossos genros.' (VALENZUELA, 2003, nossa tradução).

5 As formas referenciais não expressas, no relato em língua Shipibo-Konibo, a exemplo de expressões pronominais morfológicas e contextuais, são representadas entre parênteses, na tradução em língua Portuguesa. 
- | Tópico discursivo e tabu comunicativo em um relato Shipibo-Konibo

Na 'caracterização' da interação do passado, os referentes non 'nós' e rayos 'genros' são introduzidos e, nesse sentido, processos de referenciação em torno do referente rayos 'genros' desenvolvem a construção e configuração tópica. Ainda nesse primeiro segmento, a interação verbal em contextos que envolvem os rayos 'sogros(as) e genros' implica a restrição comunicativa, pois os genros não são considerados como bene itsa 'cunhados, lit. esposo-outro'.

O operador jawetianbi 'sendo assim' apresenta a transição do segmento tópico anterior para o segmento 'interação mediada'. Com esse operador, são apresentados exemplos da interação tradicional entre rayos; a filha como referente direto e intermediadora da fala com o genro envolvido na interação como referente indireto. Por exemplo, a expressão min bene 'seu esposo' é enunciada pela sogra diretamente à filha por meio do vocativo xonta 'garota', e o genro, por sua vez, responde indiretamente à sogra com a mediação de sua esposa.

A referenciação ao genro, no segmento 'justificativa', é realizada por meio da expressão non jawe 'nossos alguma coisa' e em seguida, non bene 'nossos esposos'. Nessa unidade tópica, o pronome de primeira pessoa, assim como sua forma do possessivo, ocorre apenas na categoria de número plural, como em noa 'nós' e non rayos 'nossos genros'. Aliás, na maior parte do relato, os referentes pronominais e alguns nominais são apresentados de maneira indefinida ou genérica. Conforme o exemplo a seguir, o pronome possessivo de terceira pessoa do singular: jawen rayos [pOs3] [rayos] 'os genros' indica o 'distanciamento' do genro:

(4) Moatian, akatikanai, yoyo ayamabireskin, 'Antigamente, nós não falávamos (com eles), e (nós) não falamos (com eles) em absoluto,' pataxbobi, winoyamakatikanai non rayos. 'em vários momentos, (nós) sequer passávamos ao lado de nossos genros.'

(5) Moa jawen rayos ocho joai oinax, beokatikanai... 'Quando (nós) víamos os genros chegando, (nós) abaixávamos a cabeça...' ...jawen rayos beisnaketian. Jaskarabo ikatikanai. '...para que os genros não vissem nossos rostos. Assim eram as coisas.' 
(6) Jawetianki jawen bakeya iki, jatianpari, yoyo akatikanai. 'Quando as filhas estavam presentes, então nós falávamos (sobre eles).' Jain jawen bake iketianpari, "min benen bakishparijaskara atanon!", 'Apenas quando as (filhas) estavam presentes, (nós dizíamos): "seu esposo pode fazer isso ou aquilo amanhã!",' jatian rayos kaai yomeraaibo, nonti akibo, winti akibo. 'então os genros saíam para pescar ou caçar e assim (eles) construíam uma canoa, e (eles) faziam um remo.' Ramakamanbi ja axebo noa keyotama iki. 'Até hoje esses costumes não foram completamente perdidos por nós.' (VALENZUELA, 2003, nossa tradução).

A maneira de apresentar o 'distanciamento' do genro corresponde aos processos de construção do objeto de discurso em contextos tradicionais de (não) interação. Com base no relato, a restrição comunicativa é também representada em cenas em que a sogra evita a aproximação espacial, como apresentado no segmento 'distanciamento', e o contato visual com o genro, exemplificado no segmento 'contato visual'. As informações apresentadas nessas unidades tópicas corroboram o desenvolvimento do tópico discursivo com as afirmações a respeito da proximidade entre os rayos.

O intertexto discursivo no segmento 'pedido ao genro' tem como referência nominal a filha, cujo determinante (à esquerda do nome) indica referentes não específicos; jawen bake(ya) 'as filhas'. Na língua Shipibo-Konibo, o elemento $\{-y a\}$ corresponde a um sufixo propriativo que tem a função de mudar um nome para um adjetivo ou modificador descritivo (VALENZUELA, 2003). Assim como no segmento 'interação mediada', há o exemplo de diálogo indireto com o genro, sendo a fala direcionada à filha, com o uso da expressão min bene 'seu esposo'. Apesar da interação mediada, com o objetivo de a sogra fazer determinados pedidos ao genro, o contexto de distanciamento é retomado no segmento tópico a seguir:

Nokon rayos ochokeax joaitian, en yoyo ayamaai, ponte en "jowe" aresai: 'Quando meu genro chega de longe, eu não converso (com ele), eu apenas (o) cumprimento impessoalmente, dizendo "(você) veio!";' nokon jawe ikemein "mia joa?" ixon, metsonboti iki.: '(ele) não é/seria meu 'alguma coisa' para (eu) perguntar (a ele): "você veio?", e (eu) pegar na mão (dele).' Jatian jawen awin joai, "mia joa?" akin akai;: 'Quando a esposa dele chega, (ela) pergunta (a ele) "você veio?";' "mia joa?" axon, jan bibainai.: 'e (ela) dizendo isso (a ele), ela (o) pega pela mão.' Non jaskaati atipanyamake, shiroma iki.: Nós não podemos (os) tratar dessa maneira, (isso) não é uma piada.' (VALENZUELA, 2003, nossa tradução).

Com relação ao uso da primeira pessoa do singular, somente o segmento 'cumprimento impessoal', que fecha o subtópico 'interação do passado', apresenta essa 
- | Tópico discursivo e tabu comunicativo em um relato Shipibo-Konibo

categoria de primeira pessoa singular tanto na forma pessoal quanto possessiva. Quando é descrito um evento de encontro com o genro que chega de algum lugar e compartilha o contexto locativo, o referente 'genro' é apresentado com a expressão nokon rayos 'meu genro', e em seguida a enunciadora se apresenta com o uso do pronome pessoal de primeira pessoa en 'eu'. Com isso, o evento descrito já apresenta a emergência de mudança na interação e a proximidade comunicativa entre rayos.

A referência da enunciadora à esposa do ponto de vista do genro é apresentada uma única vez nesse segmento mediante a expressãojawen awin 'esposa dele'. Ela descreve o contexto de interação da esposa com relação ao esposo, quando ela o segura pela mão, ao perguntar sobre sua chegada. No final desse segmento tópico, a enunciadora retoma o uso do pronome de primeira pessoa do plural non 'nós' e a descrição sobre o papel social de 'sogra' com relação ao papel social de 'genro', cujo grau de relevância social é apresentado com a expressão shiroma iki '(isso) não é uma piada'.

Os aspectos tradicionais do tabu são caracterizados no subtópico 'interação do passado', e, em específico, por meio de intertextos discursivos que exemplificam as estratégias de comunicação entre sogras e genros, tendo a filha/esposa correspondente como mediadora da interação. Nesses subtópicos, a enunciadora apresenta a relevância da categoria 'genro' por meio de mecanismos de sequência lexical, morfológica e contextual, os quais relacionam as formas de expressão e sentido referencial a essa categoria referencial.

\section{Interação do presente}

Com relação ao subtópico 'interação do presente', comecemos com a análise do segmento tópico 'interação não mediada', que se desenvolve por meio de comentários acerca da 'aproximação' entre os participantes rayos:

(8) Ramatian, ocho katanketian, "mia joa, chaki? mia joa, bake?", 'Atualmente, quando (eles) chegam de longe, (perguntamos/falamos:) "você veio, garoto? você veio, criança?",' non jawekiamaai, non bakebi keskaakin. 'e nós fazemos comida (para eles), como se (nós os) considerássemos nossas crianças/filhos.'

(9) Rama jaskarama iki, rama non winotaniai. Pataxtanibo noa niai. 'Agora isso não é assim, agora nós passamos um pouco ao lado (deles). Nós andamos um pouco próximo (a eles).' Moatian, jaskarama ikatiai. 'Antigamente (lit.até agora) isso não era assim.' (VALENZUELA, 2003, nossa tradução). 
Nesse segmento, o marcador temporal ramatian 'atualmente' introduz, por meio do recurso de intertexto discursivo, um evento comunicativo da sogra com o genro. Assim como no segmento anterior, omite-se a categoria verbal 'falar/perguntar' e este exemplo de interação no presente é apresentado: mia joa, chaki? mia joa, bake? 'você veio, garoto? você veio criança?'. Nesse segmento, a enunciadora apresenta uma referência direta ao genro presente nessa fala e reitera na linha seguinte a referência na forma de uma expressão possessiva non bakebi 'nossas crianças/filhos', o que indica aproximação e familiaridade com o genro.

Sobre o segmento tópico 'aproximação espacial', o enunciado é iniciado com a expressão temporal rama jaskarama iki 'agora isso não é assim', que encapsula o sentido do segmento 'distanciamento', de modo a negar ou atenuar, em termos de contexto comunicativo do presente, a ideia do distanciamento físico entre rayos. Apesar do contraponto temporal com relação a essa mudança no comportamento verbal, apresentado com a expressão jaskarama ikatiai 'isso não era assim', a 'mudança na interação' complementa o relato:

(10) Jatian yoyo akinmabi jan jawekibo bea moa non akai: 'apesar de (nós) não conversarmos (com eles), ele traz as comidas e nós cozinhamos'. Jatian ja joni onan-ke "nokon rayosenra ea noije" ixon: 'então o homem se dá conta disso, e (ele) diz: "minha sogra gosta de mim.". Joketian non xeamayamakin oinresa, 'se quando (eles) chegam e nós não damos o que beber (para eles), (nós) apenas (os) olhamos' bakeranon shinanai: "nokon rayosenra ea noiyamake" ikai: 'então o jovenzinho irá pensar: "minha sogra não gosta de mim"' Jaskara itima iki, jatixonbi noiti jake: 'as coisas não devem ser assim, todos (nós) devemos (os) amar/considerar.' (VALENZUELA, 2003, nossa tradução).

O termo rayos 'genros' introduzido na 'caracterização' do tabu apresenta mudanças que modificam o sentido da referência ao longo do relato. No último segmento 'mudança na interação', após a descrição de um evento no qual a sogra cozinha o alimento trazido pelo genro, é apresentado o intertexto discursivo do genro que se expressa com relação ao acolhimento da sogra. Contudo, o referente genro é recategorizado com o uso da expressão joni 'homem', que nesse contexto corresponde a uma designação de gênero a respeito do tabu comunicativo.

Em seguida, a descrição de um evento hipotético oposto ao descrito anteriormente é apresentado pela enunciadora. Ela descreve, por meio de intertexto discursivo, a contrariedade do genro após uma suposta situação de indiferença da sogra com relação ao genro. Nesse segmento textual, a referenciação ao genro é realizada com o termo utilizado no segmento 'diálogo indireto', que corresponde à expressão bakeranon 'jovenzinho'. 
- | Tópico discursivo e tabu comunicativo em um relato Shipibo-Konibo

Em seguida, na última linha do texto, ela desconsidera esse comportamento e reafirma a necessidade e emergência de maior consideração afetiva nas relações comunicativas e sociais entre rayos.

Falantes mais velhos do povo Kashibo-Kakataibo, cuja língua também é falada na Amazônia peruana e pertence à família Pano, relatam que seguiam práticas similares de tabu comunicativo (FLECK, 2013). Com base nesses relatos, futuros estudos sobre os aspectos sociointeracionais de sociedades indígenas poderão avançar o conhecimento de suas relações comunicativas, tendo em vista o desenvolvimento de pesquisas sobre as características textuais e interacionais dessas sociedades. Temas relevantes de pesquisa envolvem, por exemplo, os efeitos socioculturais da mudança na interação, assim como suas causas, no que diz respeito às relações comunicativas entre os próprios ShipiboKonibo e o contato linguístico com outras sociedades vizinhas.

\section{Considerações finais}

O desenvolvimento do Quadro Tópico tem como base os processos de introdução, retomada e progressão textual dos objetos de discurso rayos (sogro(a) e genro), e suas relações de centração e organicidade nos eventos de interação no relato analisado. Nesse sentido, a organização do tópico discursivo a respeito do tabu comunicativo em ShipiboKonibo reflete os aspectos sociocognitivos que envolvem os processos de referenciação textual e de ordenação e interdependência dos segmentos tópicos.

Tendo em vista a interrelação dos objetos referenciais com a organização dos segmentos tópico-discursivos, é na referenciação aos objetos de discurso que a enunciadora manifesta seu posicionamento a respeito do relato. Portanto, concluímos que as estratégias interacionais de referenciação e de gestão do tópico discursivo indicam variação cultural e emergência de mudança do tabu comunicativo no presente em relação a aspectos conservadores no passado.

\section{Referências}

BEAUGRANDE, R. de; DRESSLER, W. U. Introduction to text linguistics. London: Longman, 1981.

BENTES, A. C. Narrativas da Amazônia. In: FIGUIEREDO, A. (org.). Enciclopédia Cultural da Amazônia - Tomo 5 - Lendas, Mitos e Magias. v. 5. Belém: Fundação Amazônia, 2007. 
FLECK, D. W. A Grammar of Matses. 2003. Tese (Doutorado em Linguística) - Rice University, Houston, 2003.

FLECK, D. W. Panoan language and linguistics. Anthropological papers of the American Museum of Natural History. v. 99. New York, 2013.

JUBRAN, C. C. A. S. et al. Organização tópica da conversação. In: ILARI, R. (org.)

Gramática do Português Falado. v. 2. Campinas: Editora da UNICAMP, 2002. p. 341-377.

JUBRAN, C. C. A. S. Revisitando a noção de tópico discursivo. Cadernos de Estudos Lingüísticos, Campinas, v. 48, n. 1, p. 33-42, 2006.

KOCH, I. G .V. Inter-ação pela linguagem. São Paulo: Contexto, 1992.

MONDADA, L.; DUBOIS, D. Construções dos objetos de discurso e categorização: uma abordagem dos processos de referenciação. In: CIULLA, A.; RODRIGUES, B. B.; CAVALCANTE, M. M. (org.). Referenciação - Clássicos da Lingüística 1. São Paulo: Contexto, 2003. p. 17-52.

REZENDE, R. C. O tópico discursivo em questão: considerações teóricas e análise de uma narrativa literária. Cadernos de Estudos Lingüísticos, Campinas, v. 48, n. 1, p. 71-84, 2006.

VALENZUELA, P. M. Transitivity in Shipibo-Konibo Grammar. 2003. Tese (Doutorado em Linguística) - University of Oregon, Oregon, 2003.

ZARIQUIEY, R. B. A Grammar of Kashibo-Kakataibo. 2001. Tese (Doutorado em Linguística) - La Trobe University, Bundoora, 2011.

\section{Agradecimentos}

Agradecemos às professoras Edwiges Maria Morato e Anna Christina Bentes pelos valiosos comentários durante o início da redação deste trabalho, assim como aos/às pareceristas anônimos(as) que dedicaram seu tempo à revisão do manuscrito. Quaisquer erros remanescentes são de responsabilidade dos autores. 
- | Tópico discursivo e tabu comunicativo em um relato Shipibo-Konibo

O autor Raphael Barbosa, pesquisador de pós-doutorado na Universidade de São Paulo (USP), agradece à Fundação de Amparo à Pesquisa do Estado de São Paulo (FAPESP) pelo Processo no 2017/12835-0.

Anexo 1. Relato textual sobre a interação entre 'rayos'. Ranin Ama (ca. 40 anos). San Fransisco de Yarinacocha (Valenzuela, 2003:972-977, nossa tradução para o português). ${ }^{6}$

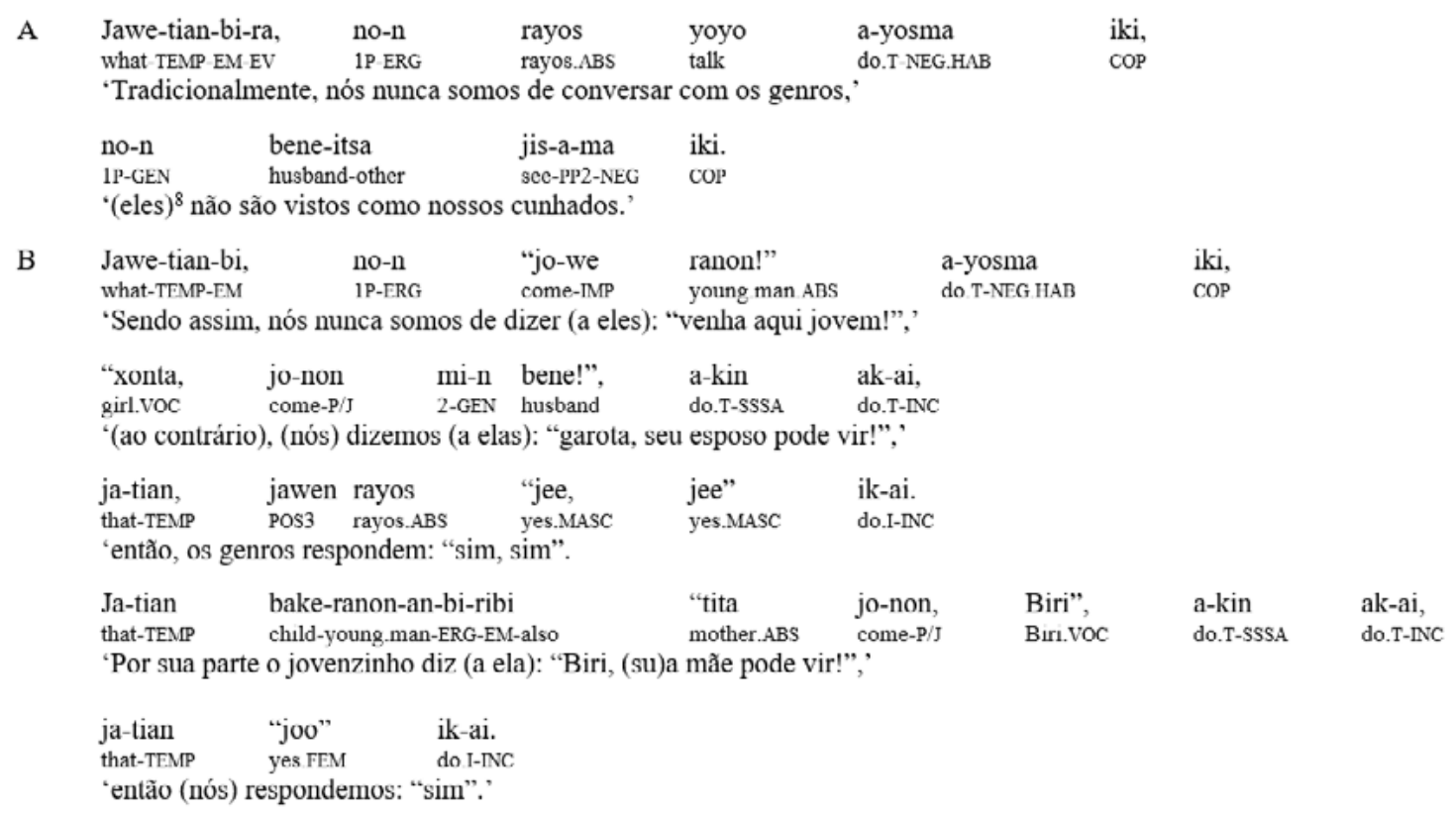

6 As abreviações usadas nas glosas correspondem aos seguintes termos em língua inglesa: $1 P$ - first person plural; $A$ - transitive subject function, a-orientation; $A B S$ - absolutive; $A G T Z$ - agentivizer; $A L L$ - allative; $A N D 2$ andative nonsingular, singular transitive; $A T$ - attenuative; $A U X$ - auxiliary; $C A U S$ - causative; $C M P L$ - completive aspect; $C O M$ - comitative; $C O P$ - copula; $D I M$ - diminutive; $E M$ - emphatic; $E R G$ - ergative; $E V$ - direct evidential; FEM - feminine; GEN - genitive; HAB - habitual; HSY2 - shorter hearsay; $I$ - intransitive (subject orientation); IMP - imperative; INC - incompletive aspect; INF - infinitive; LIM - limitative; MASC - masculine; MID - middle; NEG negative; ONOM - onomatopoeia; $P / J$ - prospective/jussive; $P D S$ - previous event, different subjects; $P L$ - plural; $P O>S / A$ - previous event, object coreferential with matrix subject; $P O S 1$ - possessive first person singular; $P O S 3$ - possessive third person singular; $P P 1$ - incompletive participle; $P P 2$ - completive participle; PREV - preventive; PROP - proprietive; PSSA - previous event, same-subject, a-orientation; PSSS - previous event, same-subject, s-orientation; PST4 - several years ago past; SDS - simultaneous event, diferente subjects; SIML - similitive; SPECL - speculative; SSSA - simultaneous event, same-subject, a-orientation; sSSS - simultaneous event, different subject, s-orientation; $T$ - transitive; TEMP - temporal; $V O C$ - vocative. 


$\begin{array}{lllllllll}\text { Rama-kaman-bi } & \text { no-a } & \text { no-n } & \text { rayos betan yoyo i-ama-ai, } & \text { no-a } & \text { ja-ska-ra } & \text { iki. } \\ \text { now-LIM-EM } & \text { 1P-ABS } & \text { 1P-GEN } & \text { rayos com speak do.I-NEG-LNC } & \text { 1P-ABS } & \text { that-SIML-EV } & \text { COP }\end{array}$
'Até hoje nós não falamos diretamente com nossos genros, nós somos assim.'

$\begin{array}{llllll}\begin{array}{l}\text { Wetsa-nko-bo } \\ \text { other-ALL-PL. }\end{array} & \text { ka-ai-bi } & \text { no-n } & \text { oin oin-res-ai } & \text { no-n } & \text { rayos. } \\ \text { go-SDS-EM } & \text { 1P-ERG } & \text { see-see-just-NC } & \text { 1P-GEN } & \text { rayos.ABS }\end{array}$

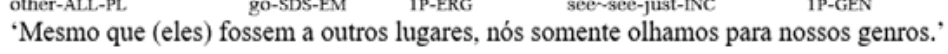

\begin{tabular}{|c|c|c|c|c|c|c|}
\hline $\begin{array}{l}\text { No-n } \\
1 \text { P-GFN }\end{array}$ & $\begin{array}{l}\text { jawe } \\
\text { what ABS }\end{array}$ & $\begin{array}{l}\text { i-ke-mein, } \\
\text { be-PDS-SPECL }\end{array}$ & $\begin{array}{l}\text { no-n } \\
1 \mathrm{P}-\mathrm{GFN}\end{array}$ & $\begin{array}{l}\text { bene } \\
\text { husband ABS }\end{array}$ & $\begin{array}{l}\text { i-ke-mein, } \\
\text { be-PDS-SPECL }\end{array}$ & $\begin{array}{l}\text { rayos } \\
\text { rayos } A B S\end{array}$ \\
\hline $\begin{array}{l}\text { lo-n } \\
\text { P-ERG }\end{array}$ & $\begin{array}{l}\text { yoka-ti } \\
\text { ask-INF }\end{array}$ & & & & & \\
\hline
\end{tabular}

$\begin{array}{lll}\text { no-n } & \text { yoka-ti } & \text { iki. } \\ \text { 1P-ERG } & \text { ask-INF } & \text { AUX }\end{array}$

'(Eles) seriam talvez nossos 'alguma coisa', ou (eles) seriam talvez nossos esposos para, aos genros, nós fazermos perguntas?'

Jakon-shoko a-kin-res no-n rayos a-ti ja-ke.

good-DIM do.T-SSSA-just 1P-GEN rayos.ABS do.T-INF exist-CMPL.

'(Nós) devemos ter respeito a nossos genros.'

D Rama-tian, ocho ka-tan-ke-tian, “mi-a jo-a, chaki? mi-a jo-a, bake?",

now-TEMP far go-go.do.return-P-DS 2-ABS come-PP2 boy.VOC 2-ABS come-PP2 child.VOC

"Atualmente, quando (eles) chegam de longe, (perguntamos/falamos:) "você veio, garoto? você veio, criança?",

no-n jaweki-a-ma-ai, no-n bake-bi keska-a-kin.

1P-ERG thing-do.T-NEG-NC 1P-GEN child-EM SLM-do.T-SSSA

'e nós fazemos comida (para eles), como se (nós os) considerássemos nossas crianças/filhos.'

E Moa-tian, a-kati-kan-ai, yoyo a-yama-bires-kin,

already-TEMP do.T-PST4-PL-INC speak do.T-NEG-purely-SSSA

'Antigamente (lit.até agora), Nós não falávamos (com eles), e Nós não falamos (com eles) em absoluto,'

$\begin{array}{llll}\text { patax-bo-bi, } & \text { wino-yama-kati-kan-ai } & \text { no-n } & \text { rayos. } \\ \text { next.to-PL-EM } & \text { pass-NEG-PST4-PL-INC } & \text { 1P-GEN } & \text { rayos.ABs }\end{array}$

'em vários momentos, (nós) sequer passávamos ao lado de nossos genros.'

F Rama ja-ska-ra-ma iki, rama no-n wino-tani-ai. Patax-tani-bo no-a ni-ai. now that-SIML-EV-NEG COP now 1P-ERG pass-ATT-INC next-ATT-PL 'Agora isso não é assim, agora nós passamos um pouco ao lado (deles). Nós andamos um pouco próximo (a eles).'

Moa-tian, ja-ska-ra-ma i-kati-ai.

already-TEMP that-SIML-EV-NEG do.I-PST4-INC

'Antigamente (lit.até agora) isso não era assim.'

G Moa jawen rayos ocho jo-ai oin-ax, beo-kati-kan-ai...

already POS3 rayos.ABS far come-PP1 see-PSSS lower.head-PST4-PL-INC

'Quando (nós) víamos os genros chegando, (nós) abaixávamos a cabeça...'

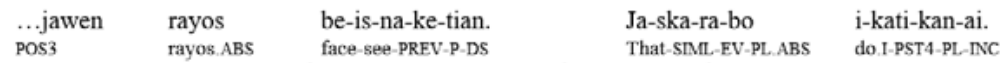

'...para que os genros não vissem nossos rostos. Assim eram as coisas.' 


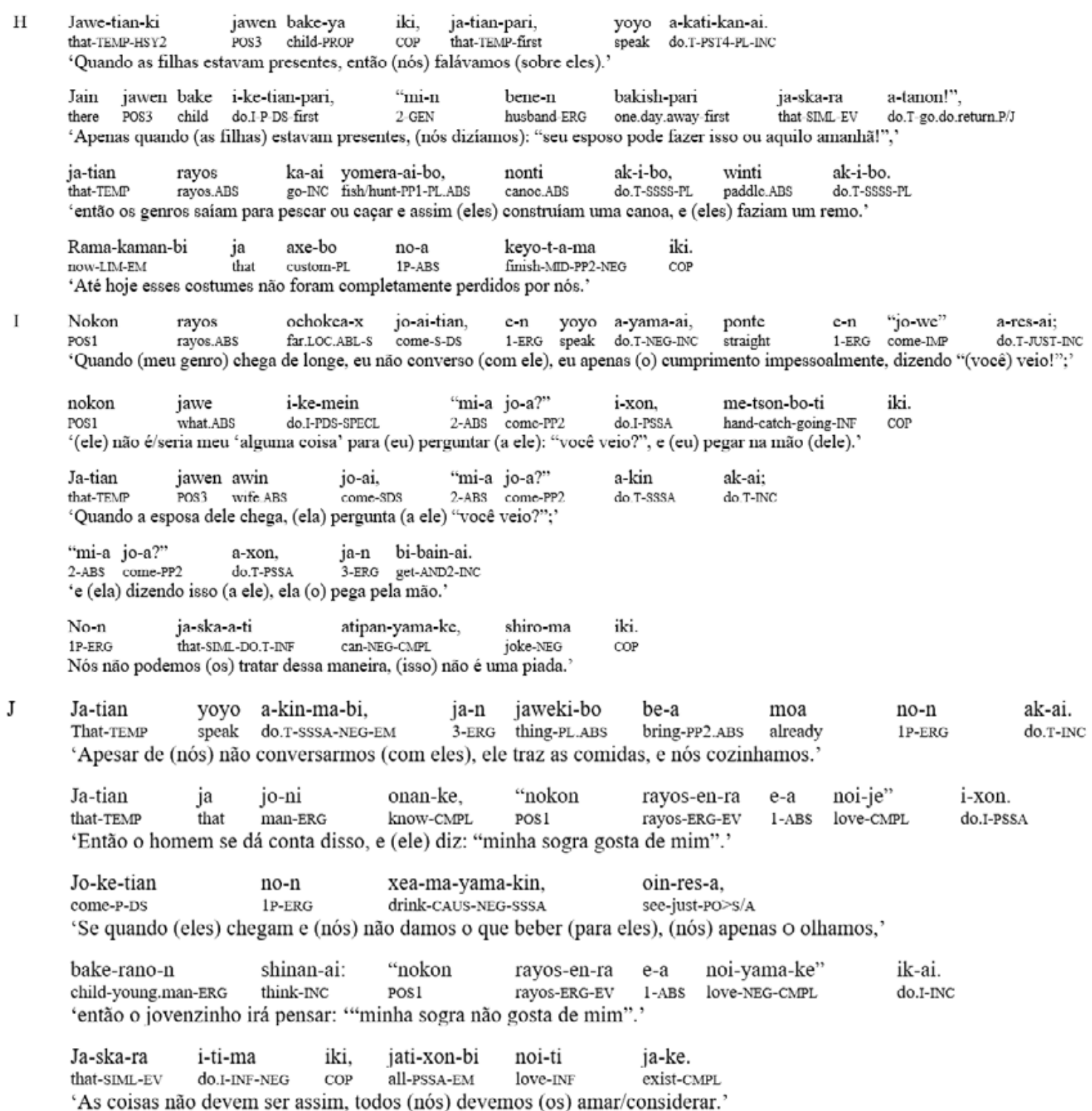


COMO CITAR ESTE ARTIGO: BARBOSA, Raphael Augusto Oliveira; REZENDE, Renato Cabral. Tópico discursivo e tabu comunicativo em um relato Shipibo-Konibo. Revista do GEL, v. 17, n. 1, p. 12-28, 2020. Disponível em: https://revistas.gel.org.br/rg

DOI: http://dx.doi.org/10.21165/gel.v17i1.2751

Submetido em: 13/10/2019 | Aceito em: 05/06/2020 